\title{
Interpretation of brand penetration figures that are reported by sub-groups
}

Received: 5th December, 2005

\section{John Dawes}

is an assistant professor in the Ehrenberg-Bass Institute for Marketing Science at the University of South Australia. His research interests are market structure analysis and pricing. John conducts research for many leading companies in Australasia, including Goodman Fielder, Orlando-Wyndham and Insurance Australia Group.

\begin{abstract}
Managers are often required to interpret key brand performance measures such as penetration (the proportion of people who bought at least once) and average purchase frequency (number of times the brand is bought in a set period) that are presented according to certain categorisations of the population, such as by demographic groups. Such categorisations may also include psychographics, for example, but this analysis chooses to focus on demographics for the purposes of illustration. Brand performance measures may vary across these demographic groups, which presents a challenge for interpretation. This is because it is not easy to distinguish between the variance due to brand segmentation, and the variance that is due to variations in category buying among those demographic groups. This paper shows how to incorporate category level information in order to create 'theoretical' or expected brand performance measures for each demographic. The actual figures can then be compared with the expected figures, which makes exceptions or deviations that could signal brand-level segmentation easier to identify. The approach is tested on the breakfast foods category in Australia. The results show that over 95 per cent of the variance in brand performance across demographic groups is simply attributable to (a) the overall size of the brand; (b) the penetration of the category into each demographic; and (c) the average purchase frequency with which each demographic group buys the category. In this category, brand-level segmentation accounted for a very minor proportion of the difference in penetration levels for brands across various demographic groups. That said, the analysis method did identify two brands with markedly different performance levels compared with their expected levels, in specific demographics. One brand overperformed with younger families, and the other underperformed with larger families. These performance levels were checked against a subsequent year of data and found to be robust. The main managerial implication of this study is that a simple model can be used to identify 'expected' brand performance levels, and the method

clearly shows that almost all the variation in brand penetrations into various

demographic sub-groups is simply attributed to brand size and category level effects.
\end{abstract}

John Dawes

Ehrenberg-Bass Institute for

Marketing Science,

University of South

Australia, 70 North Terrace,

Adelaide SA 5000,

Australia

Tel: +61 883020592 ;

Fax: +61 8830 20442;

E-mail: john.dawes@

marketingscience.info

\section{INTRODUCTION}

Many marketing professionals, particularly those in consumer packaged goods companies, spend money on consumer panel data to obtain and analyse brand performance measures. Examples of such services are AC Nielsen's Homescan consumer panel, IRI's Consumer 
Network panel and TNS' Worldpanel. Such information is seen as indispensable in the consumer goods arena, as feedback on brand performance is vital to sustain competitiveness and appropriately adjust marketing mix activities.

Typical brand performance measures are penetration (the proportion of people who bought at least once) and average purchase frequency. Average purchase frequency is the basis for additional loyalty measures such as share of category requirements and proportion of solely loyal buyers. ${ }^{1}$ These measures are often presented for specific demographic groups - for example, the proportion of males who bought brand $X$, or the number of times small families bought brand $Y$. An issue with the interpretation of this information is that it can be difficult to identify whether a given penetration figure is high, low or 'approximately right' in the context of the brand's overall marketplace position.

For example, Table 1 shows penetration levels for an Australian breakfast cereal brand, 'Nutri-Grain', in four demographic groups. It shows that this brand enjoys higher penetration into the 35-44-year-old principal shopper demographic, at 48 per cent, compared with only 22 per cent in the $55+$ years demographic. The brand penetration into the general population is 33 per cent. One conclusion that can be drawn from these data is along these lines:

Nutri-Grain is particularly popular among the 35-44-year demographic, but is less popular with older buyers aged $55+$ years.

This information has a range of possible marketing strategy implications. For example, one could deduce that this brand should be targeted at 35-44-year-olds, as they appear to favour it. Alternatively, one could suggest that the firm should try to target older consumers for this brand, as they presently under-buy it. Or, indeed, that more research should be conducted to determine why the brand is more popular with the 35-44-year-old demographic and not the 55+ years demographic. Perhaps the brand is bought by parents for their children, and people with children at home are more likely to be in the 35-44 year age group demographic. Before proceeding with any of these avenues, however, it is worthwhile to consider more fully how to interpret the figures.

\section{BRAND PERFORMANCE VS BRAND SEGMENTATION}

Interpretation of differences in performance across population sub-groups leads the discussion from the brand performance arena to that of brand segmentation. Brand performance concerns how many people buy the brand and how often they buy it. Brand segmentation pertains to differences in the user profiles of competing brands. This means that the variables used to examine brand performance are related to, but slightly different from those used to examine brand segmentation. This is illustrated below using a hypothetical example.

- Illustrative brand performance analysis question: What proportion of males under 30 years buy Stolichnaya vodka in a 12 -month period?

- Illustrative brand segmentation analysis question: Of the people who buy Stolichnaya vodka, what proportion are males under 30 years - and how does this compare with other brands?

Both these variables, namely brand performance within a demographic vs user profiles for a brand, are based on how many people buy the brand in a particular time period. This commonality 
Table 1: Nutri-Grain

\begin{tabular}{ll}
\hline Demographic of principal shopper & $\begin{array}{l}\text { Percentage buying at least } \\
\text { once in } \mathbf{5 2} \text { weeks (penetration) }\end{array}$ \\
\hline Age $<35$ years & 39 \\
Age 35-44 years & 48 \\
Age 45-54 years & 30 \\
Age 55+ years & 22 \\
Population & 33 \\
\hline
\end{tabular}

means that if there is some brand-level segmentation, then there must be some differences in brand performance among demographics. Likewise, if there are brand performance differences among sub-groups, there must be brand-level segmentation. From a brand manager's perspective, the extent to which the brand's user base differs from the competition or the category average may not be considered a highly strategic issue. If it is viewed in the context of brand performance, however, the fact that a brand performs particularly well or particularly poorly among a purchasing sub-group may be of intense interest. It may point to avenues for future growth, or highlight particular strengths or weaknesses of the brand to be further invested or acted upon. The paper now briefly examines prior research on the extent to which the user profiles of competing brands differ.

\section{EVIDENCE AS TO BRAND-LEVEL SEGMENTATION}

Several comprehensive studies have examined the extent to which the user profiles of competing brands differ.

Hammond et al. ${ }^{2}$ examined 23 consumer packaged goods categories and found the average user profiles differed by only 3 percentage points. While the average was 3 , in many cases there were examples of differences of 5 or 6 points. In a replication study, Kennedy et al. ${ }^{3}$ examined 42 product categories using the well-known UK 'TGI index'. The user profiles comprised demographic, media viewing and attitudinal data. They again found the average difference among brand user profiles to be only 2 percentage points, with more marked differences for categories such as cigarettes (average deviation 6 points), Tessa accounts (5 points) and cat food (4 points). The same approach was used by Fennell et al., ${ }^{4}$ who examined data for over 50 product categories in the USA. They also found that demographics and psychographic variables explained little in terms of brand choice.

These results suggest that marked brand segmentation is not the norm generally, there is only up to a $3-5$ percentage point difference from the average in the user profiles of competing brands. As stated above, for a manager, such small differences in brand-level segmentation may appear too small to be relevant. If this is considered in the context of brand performance, however, and we wish to understand the composition of overall brand performance - then such differences may become more relevant. If the average difference between competing brands on demographic measures is 3 percentage points from the average across all brands, then the difference between two particular brands could easily be closer to 6 points. Suppose there are four brands, and their proportions of users who have demographic characteristic $X$ are, respectively, 18, 21, 26 and 27 per cent. The average is 23 and the average absolute deviation is 3.5 percentage 
points. However, the difference between the two brands with the highest and lowest proportions of users with this characteristic is 9 points (18 vs 27). Such differences may be of use to the marketer interested in understanding the overall composition of brand performance among various buying sub-groups. Therefore, there is some rationale for investigating brand performance among sub-groups, in particular to identify if there is a readily applicable model that could explain the variation seen in brand performance among such sub-groups.

\section{CREATE 'THEORETICALLY EXPECTED' FIGURES}

The starting point for such a model is to create theoretically expected brand penetration figures - in other words, what the penetrations into each demographic group 'should be'. The three key variables that will dictate the expected levels of brand penetrations into a demographic sub-group are (1) overall brand penetration; (2) the proportion of the demographic group that purchases the category at least once in a time period (ie category penetration) and (3) the average number of times that demographic group buys the category in the time period. If it is possible to account for the variance in penetration caused by these three variables, then the remainder is indicative that the brand has particular appeal to specific groups in the population. Each variable is now briefly discussed.

\section{Overall brand size}

Consider an $r \times c$ matrix of demographic groups (rows) and brands (columns), with the cells representing the brand penetrations for each demographic and brand combination. It is intuitively apparent that the major factor influencing the variance 'along each row' will be the overall size of the brand. A big brand would, overall, be expected to be bigger in any specific demographic group compared with a small brand.

\section{Differences in category penetration across demographics}

Continuing with the idea of an $r \times c$ matrix of demographic groups (rows) and brands (columns): the brand may have considerable variation 'down a column' - in other words, a larger proportion of group $A$ buy the brand than group $B$. An important factor that will influence the penetration levels of a particular brand into each demographic group is the penetration of the category into those demographic groups. Some demographic groups may have higher or lower proportion of people who buy the category at least once in a given period. As an example, young people are more likely to buy from the 'alcopop' pre-mixed drinks category than older people, so penetration levels for any 'alcopop' brand will be higher among young people than older people. This variation in category penetration will be a major factor in explaining the variations in brand penetration between each demographic. A higher category penetration will be positively related to higher penetration levels for all or most brands.

\section{Differences in category purchase frequency across demographics}

Table 1 showed that 'Nutri-Grain' had a high penetration into the 35-44-years age group compared with other age groups. As stated previously, this may simply be because the category penetration for breakfast cereals is higher in this group. However, variation in the 
Table 2: Australian breakfast cereal purchase frequency across demographics

\begin{tabular}{lcc}
\hline & $\begin{array}{l}\text { Percentage buying category at } \\
\text { least once in } \mathbf{5 2} \text { weeks }\end{array}$ & $\begin{array}{l}\text { Average no. purchase } \\
\text { occasions per } \mathbf{5 2} \text { weeks }\end{array}$ \\
\hline $\begin{array}{l}\text { Age of principal shopper } \\
<35 \text { years }\end{array}$ & 94 & 13 \\
35-44 years & 98 & 17 \\
$45-54$ years & 96 & 15 \\
$55+$ years & 94 & 13 \\
Population average & 95 & 14 \\
Household size & 93 & 10 \\
1-2 members & 98 & 16 \\
members & 99 & 20 \\
4 members & 100 & 25 \\
$5+$ members & 95 & 14 \\
Population average & & \\
\hline
\end{tabular}

penetration level for a given brand or brands among various demographics may also pertain to the fact that the category purchase frequency may differ across demographics. Particular age groups for example, families with more people in the household - may buy breakfast cereal more often in a given time period. Penetration and purchase frequency are, generally speaking, two aspects of the same phenomenon - namely, a propensity to buy in a time period. ${ }^{5}$ Therefore, higher penetrations will generally accompany higher purchase rates and vice versa. However, penetration may exhibit little difference between demographic groups but purchase frequency might vary considerably. In some popular categories, the penetration levels for the category may be very high, at 90 per cent or more for a period such as a year for the overall population, and also for any of the normally specified demographic sub-groups. Yet category purchase frequency may still vary considerably across these groups. This is because penetration pertains to buying once, whereas purchase frequency pertains, obviously, to the number of times bought. Once category penetration is very high, there can be considerable variance in category purchase frequency but minimal variation in penetration.
Table 2 illustrates this point, showing that category penetrations for each demographic group are over 90 per cent, but purchase frequency varies considerably across the demographic groups. Households with a principal shopper aged 35-44 years, or households with 4 or $5+$ members, buy the category more often than other demographic groups.

When this phenomenon occurs, it is likely that there will be additional variation in brand penetrations, for most or all brands, beyond that explained simply by differences in category penetration. This is because if a particular demographic group $A$ buys the category more frequently than other demographic groups, then a comparatively higher proportion of that group $A$ will buy any particular brand at least once in the period. The reason is that consumers typically buy from a repertoire of brands, ${ }^{6}$ and this repertoire size increases as per-period category purchasing frequency increases. ${ }^{7}$

This discussion suggests that in order to determine the 'theoretically expected' brand penetration level into a particular demographic, it is necessary to control for the effects of all three factors:

- overall brand size, which will be a major factor in the variance in 
penetrations for any brand into any demographic group;

- varying category penetration in different demographic groups, which will lead to varying brand penetrations between demographics;

- varying category purchase frequency in different demographic groups, which will further raise or lower brand penetrations for most or all brands, within that demographic.

By factoring in these three variables, it should be possible to create 'theoretically expected' penetrations for a group of competing brands across a set of demographic variables. If these factors explain the majority of the variance in brand penetrations, then any resultant marked differences between the actual penetrations and the expected penetrations are indicative that the brand has particular appeal or lack of appeal to a particular demographic group. The paper now explains the approach taken to derive the 'expected' penetration figures.

\section{Analysis method}

The analysis method to derive expected penetrations is to construct a multiple regression model with penetration for each brand into each demographic group as the dependent variable. The three independent variables are: overall brand penetration, category penetration for the demographic group and category purchase frequency for the demographic group.

The proposed model is therefore:

Brand penetration into demographic group $=\beta_{0}+\beta_{1}$

${ }^{\star}$ penetration into population $+\beta_{2}$

${ }^{\star}$ category penetration into demographic group $+\beta_{3}$

${ }^{\star}$ category purchase frequency for demographic group + error
The approach is tested using data on five breakfast cereal brands, taken from a consumer panel comprising approximately 2,000 households for the 12 months to December 2001. Breakfast cereal is an excellent vehicle for this purpose, as it is a category that exhibits marked differences among user profiles. ${ }^{8,9}$ The results are validated on a second data set for the same product category, comprising the 12 months to December 2002. Note the regression analysis is conducted using the aggregate level brand data, not at the level of individual buyers.

\section{RESULTS}

The results show that this comparatively simple model results in an outstanding level of fit with an adjusted $R^{2}>0.95$. The details of the model are shown in Appendix 1. The resultant 'theoretically expected' brand penetrations are shown in Table 3.

A visual inspection of the observed values compared with the theoretically expected values in Table 3 shows that the model fits extremely well. The mean absolute deviation between observed and expected is only 3.2. In other words, the model corrects estimates of brand penetrations into each demographic with an average level of inaccuracy of around three penetration points.

\section{Discussion}

This straightforward analysis using overall brand size, the category penetration exhibited by each demographic group and the average rate of category purchasing has accounted for almost all the variation in brand penetrations. If there are any marked differences between the actual figures and these derived expected figures following this process, this indicates some demographic-based 
Table 3: Comparison of observed penetrations vs theoretically estimated (2001 data)

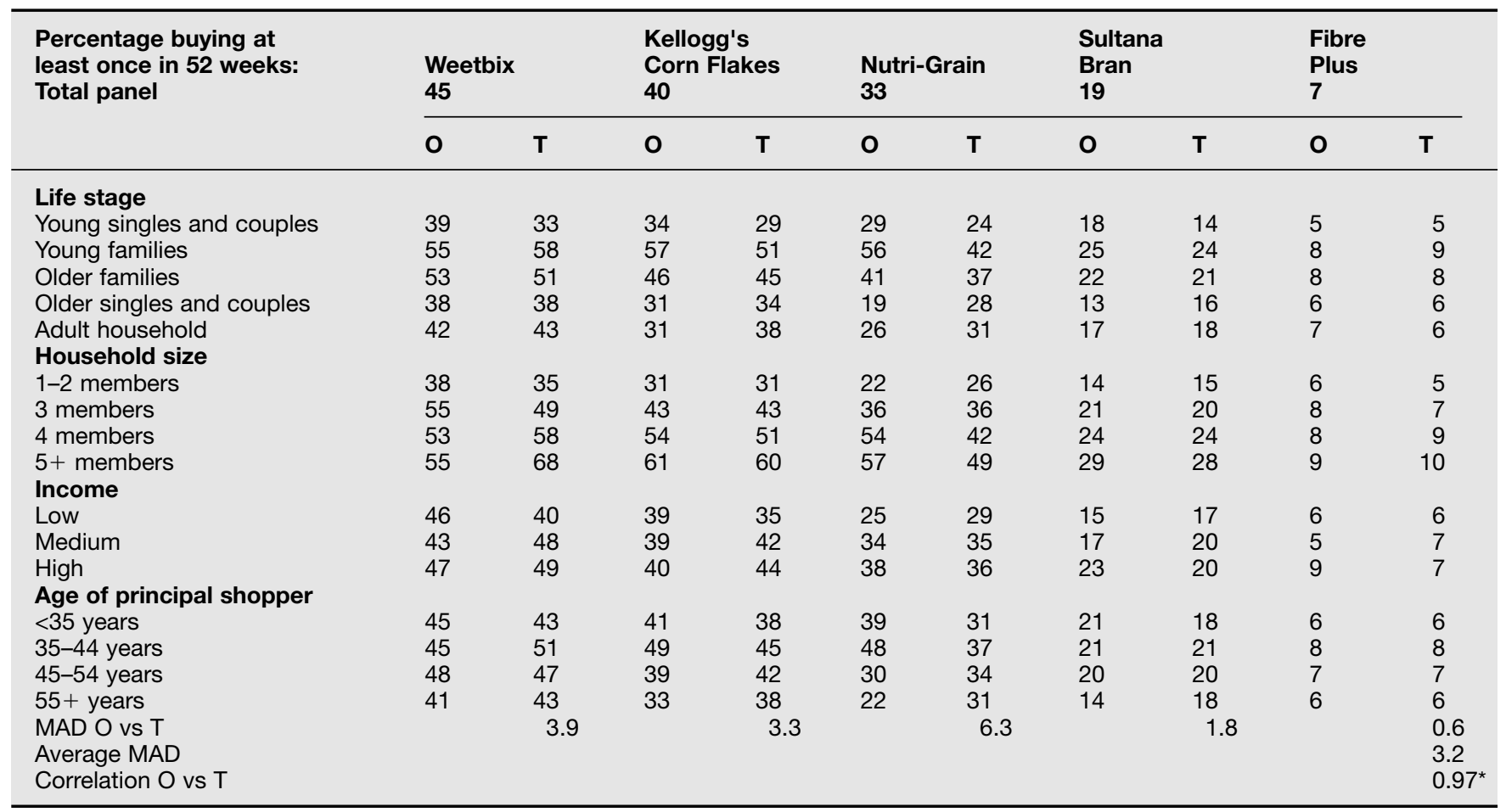

*Note the correlation coefficient here is not completely comparable with the $R^{2}$ statistic from the regression model: this is because the regression model uses log-transformed variables, whereas this is the correlation among the variables transformed back from logs MAD; mean absolute deviation; O: observed penetrations; T: theoretically estimated

segmentation (or residual error, discussed later). The comparison between actual and expected penetrations in Table 3 now shows very clearly that:

- Weetbix appears to have a lower than expected penetration into the large-household $(5+$ members $)$ demographic (55 vs 68 per cent expected).

- Nutri-Grain appears to have higher than expected penetration into the young families demographic (56 per cent vs 42 per cent expected).

These are the most marked differences in the data. There are other instances where the difference between actual and theoretically expected figures are more than a few per cent, but this paper will focus on these two larger deviations, as they also appear in an analysis of further data for the same category, which appears later in the paper.

To elaborate on the differences between actual and expected figures for the two brands above, Weetbix obtains a penetration figure into young families of 55 per cent. This compares with its population penetration of 45 per cent. The difference is partly explainable by young families having a higher penetration figure for the category that is, 99 per cent compared with 95 per cent, which is 4 per cent higher in proportional (and coincidentally, also in absolute) terms. When controlling for the fact that young families have a higher category purchasing rate, however, the expected figure for Weetbix is 68 per cent. Likewise, Nutri-Grain has a penetration into the population of 33 per cent, and in the young families demographic it is higher, at 56 per cent. 
Even allowing for the fact that young families have a higher penetration for breakfast cereal and also a higher category purchasing rate, this figure is higher than it 'should be', with the estimated figure being 42 per cent. Therefore, these results give some indication that Weetbix has somewhat of a lack of appeal for large families compared with what it should have and that Nutri-Grain has excess appeal for young families compared with what it should have.

\section{Replication}

It is important to note that these findings are based on only one data set. It is difficult unequivocally to distinguish that the differences between actual and theoretically expected figures are indeed attributable to brand segmentation, as opposed to just estimation error. Therefore, the data were checked to determine whether the same results are found in a subsequent period. The data for the following year were analysed using the same approach. This additional analysis found the same result. The regression model for 2002 produced virtually the same coefficients and the same level of fit, with an adjusted $R^{2}$ of 0.99). The model details for 2001 and 2002 are shown in Appendix 1. As was found in the 2001 data, Weetbix again had markedly lower than expected penetrations into the large families demographic group (55 per cent vs 68 per cent expected), and Nutri-Grain again had higher than expected penetrations into young families (57 per cent vs 40 per cent expected). In 2002, Nutri-Grain also had a somewhat larger difference between expected and actual penetration into the 'principal shopper age $<35$ years' demographic (46 per cent actual vs 29 per cent expected). This difference is larger than, but consistent with, the 2002 result, where it exhibited a 39 per cent actual vs 31 per cent theoretical penetration. The actual and model-estimated figures for 2002 are shown in Appendix 2.

\section{Discussion}

For the manager involved in such a category, such findings would suggest useful avenues for marketing strategy and research. For the Weetbix brand manager, the question is - why does Weetbix apparently under-perform in the large household demographic? Is there some lack of appeal for this product by children in such households? Are there some strategic options for remedying the situation? For the brand manager for Nutri-Grain, this brand seems to have particular appeal to the young families groups. Is this due to some planned strategy, or has it just 'happened'? How can this favourable situation be efficiently preserved? This analysis has revealed these issues for consideration. Without the analysis model, the brand manager would only have the raw information that Nutri-Grain, for example, has varied penetrations in a range of demographic groups. In the 'life stage' classification, as an example, these penetrations range from 29 per cent to 56 per cent, compared with 33 per cent for the population as a whole. The analysis provides a basis for understanding whether a particular penetration figure is high, low or 'about right'.

\section{CONCLUSION AND IMPLICATIONS}

The implication for marketing managers and analysts from this study is, first, that a relatively simple model can be constructed to create theoretically expected values for brand penetrations across demographic or other customer sub-groups. Aggregate level data can be used; individual 
purchases are not required. This is important because panel data providers are often reluctant to supply individual purchase records. The model created here closely mirrors the variation in brand performance across demographics by adjusting for the penetration and purchase frequency of the category into each demographic group, and the penetration of the brand into the overall population. The result is a series of 'expected' brand penetrations into each demographic, from which the actual penetration figures can be compared and contrasted. The model was tested against a further year of data and found to be robust. The main finding is that the penetration levels for a brand into a given demographic sub-group are almost all accounted for by the size of the brand in the population, the penetration level of the category into that demographic group and the frequency with which that demographic group buys the category. Once these basic factors are accounted for, there is little variation left to be attributed to brand-level segmentation in this test category. However, the modelling method is also sensitive enough to discern that one brand particularly under-performed in the young households demographic, and one other brand markedly over-performed in the same demographic. Results such as this would be of use to the brand manager seeking to dissect the reasons for their brand's overall marketplace position and to identify possible options for growth.

\section{References and notes}

1 Ehrenberg, A. S. C. (2000) 'Repeat buying - Facts, theory and applications', Journal of Empirical Generalisations in Marketing Science, Vol. 5, pp. $392-770$.

2 Hammond, K., Ehrenberg, A. S. C. and Goodhardt, G. J. (1996) 'Market segmentation for competitive brands', European Journal of Marketing, Vol. 30, No. 12, pp. 39-49.

3 Kennedy, R., Ehrenberg, A. and Long, S. (2000) 'Competitive brands' user-profiles hardly differ', in
Market Research Society Conference (UK). Market Research Society (UK), Brighton, 17th March.

4 Fennell, G., Allenby, G. M, Yang, S. and Edwards, Y. (2003) 'The effectiveness of demographic and psychographic variables for explaining brand and product category use', Quantitative Marketing and Economics, Vol. 1, pp. 223-244.

5 Within any particular product category, this is indeed the case. Brands bought by more people in a period are expected (theoretically and empirically) to be bought more often. Certain categories may be bought by a small number of people, however, but the people who buy those categories may buy them quite often. Examples are insulin, or live food for exotic pets.

6 Ehrenberg (2000) op. cit

7 Stern, P. and Hammond, K. (2004) 'The relationship between customer loyalty and purchase incidence', Marketing Letters, Vol. 15, No. 1, pp. 5-19.

8 Hammond et al. (1996) op. cit.

9 Kennedy et al. (2000) op. cit.

\section{APPENDIX 1: REGRESSION MODEL DETAILS}

\section{Assumptions}

Several assumptions of regression analysis must be met in order to yield correct results. These all relate to the error terms. The outcomes of the analysis are briefly summarised in the context of these four assumptions.

1. Mean of the probability distribution of the errors is zero. If the average of all errors is not zero, this indicates a systematic bias in the predictions. The error terms in the models for 2001 and 2002 had a mean of zero.

2. Error terms have constant variance for all values of the independent variable(s). Heteroskedasticity in the errors means that some estimates are less accurate than others. In this case, the residuals from an initial ordinary least squares regression revealed unequal error variance. This was remedied by transforming all variables to natural logs, then transforming the fitted estimate back using the $\mathrm{e}^{\wedge \text { fitted }}$ formula. 
Table 4: Regression model summary (2001 data)

\begin{tabular}{|c|c|c|c|c|c|}
\hline ANOVA & DF & SS & MS & $\mathbf{F}$ & Sig. $\mathbf{F}$ \\
\hline Regression & 3 & 855.0 & 285.00 & 14,895 & $<0.0001$ \\
\hline Residual & 77 & 1.5 & 0.02 & & \\
\hline Total & 80 & 857.0 & & & \\
\hline Coefficients & & SE & t-ratio & & $p$-value \\
\hline Ln brand penetration overall & 1.02 & 0.02 & 45 & & 0.0001 \\
\hline Ln category penetration & -0.45 & 0.04 & -11 & & 0.0001 \\
\hline Ln category avg. purchase rate & 0.75 & 0.06 & 12 & & 0.0001 \\
\hline
\end{tabular}

Adjusted $R^{2}=0.99$

Linear regression model statistics relate to log transformed variables

Dependent variable: brand penetrations into each demographic group

Independent variables: overall brand penetrations into the population; category penetration for each demographic group

$\mathrm{DF}=$ degrees of freedom; $\mathrm{SS}=$ total sum of squares; $\mathrm{MS}=$ mean square; $\mathrm{F}=\mathrm{F}$-statistic; $\mathrm{SE}=$ standard error of coefficients; $L n=$ natural log of the variable

Table 5: Regression model details (2002 data)

\begin{tabular}{lccccc}
\hline ANOVA & DF & SS & MS & F & Sig. F \\
\hline Regression & 3 & 867.0 & 289.00 & 11,348 & $<0.0001$ \\
Residual & 77 & 2.0 & 0.03 & & \\
Total & 80 & 869.0 & & $\boldsymbol{p}$-value \\
\hline Coefficients & & SE & t-ratio & 32 & 0.0001 \\
\hline Ln brand penetration overall & 0.98 & 0.03 & -8.8 & 0.0001 \\
Ln category penetration & -0.43 & 0.05 & 10 & 0.0001 \\
Ln category avg. purchase rate & 0.76 & 0.07 & & & \\
\hline
\end{tabular}

Adjusted $R^{2}=0.99$

Linear regression model statistics relate to log transformed variables

Dependent variable: brand penetrations into each demographic group

Independent variables: overall brand penetrations into the population; category penetration for each demographic group

$\mathrm{DF}=$ degrees of freedom; $\mathrm{SS}=$ total sum of squares; $\mathrm{MS}=$ mean square; $\mathrm{F}=\mathrm{F}$-statistic; $\mathrm{SE}=$ standard error of coefficients; $L n=$ natural log of the variable

3. The probability distribution of the errors is normal. This assumption was mildly violated, with a skewness of the distribution of errors of -0.82 $(\mathrm{SE}=0.27)$ and kurtosis of 1.28 $(\mathrm{SE}=3)$, but not severely enough to bias the estimates.

4. The error terms are independent that is, the value of one error has no effect on the value of others. This was examined using the Durbin-Watson statistic, which was 1.9. This indicated an absence of correlation among the errors.

A further point relating to the analysis was that there was extreme collinearity between category penetration and category purchase frequency. As this paper makes no substantive use of the regression coefficients, however, rather it merely utilises the fitted values, this was not deemed to be problematic. The effect of removing one of the collinear variables was tested, and while it did not alter the adjusted $R^{2}$ appreciably, the fitted estimates from that model exhibited a larger MAD of 5.5, compared with 3.2 in the model as presented. Therefore, there were good grounds for preferring the model with some collinearity among the independent variables. 


\section{APPENDIX 2: REPLICATION OF RESULTS FOR 2002 DATA}

Table 6: Comparison of observed penetrations vs theoretically estimated (2002 data)

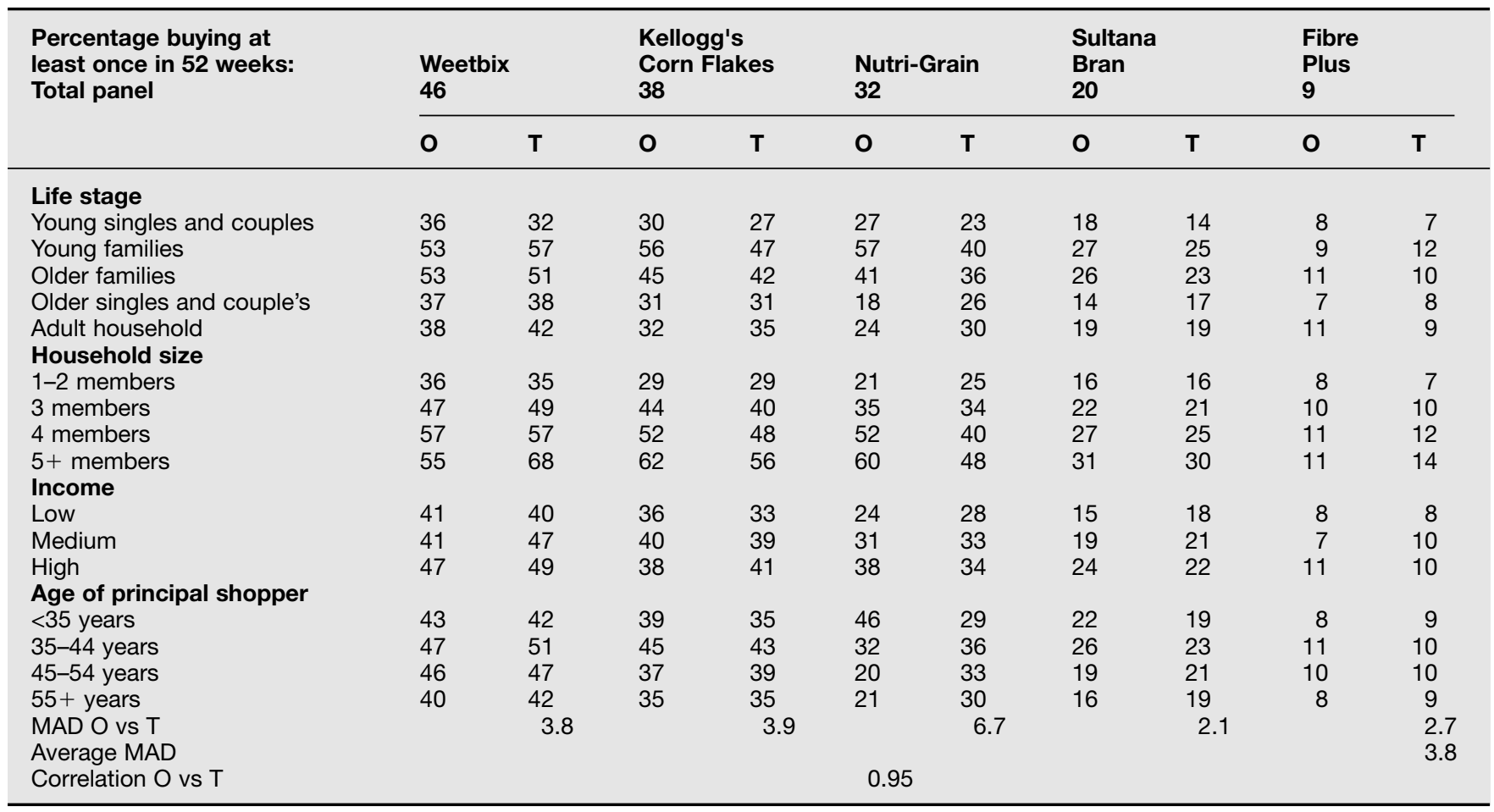

MAD: mean absolute deviation; O: observed penetrations; T: theoretically estimated 